\title{
Perfiles
}

ROODY RÉSERVE

\section{Sudáfrica: diez años después del Apartheid}

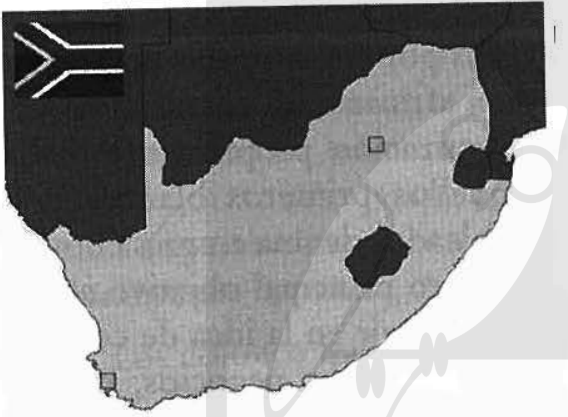

A principio de la década de los noventa, en el contexto de la liberación de Nelson Mandela y de la celebración de las primeras elecciones multiraciales en Sudáfrica, estaban reunidos todos los ingredientes para que este país fuera un caso más en el rosario de secuelas catastróficas que dejó la colonización europea en el continente negro. Sin embargo, diez años después se llega a la feliz conclusión que el espectro de la guerra civil, la limpieza étnica, y las absurdas $y$ repugnantes masacres se ha alejado, al parecer, para siempre.

Mandela, sin duda, pasará a la historia como el más grande de todos los africanos después de Toussaint Louverture. Éste mostró una inteligencia increíble hace más de doscientos años en la preparación de la primera revolución victoriosa y abolición de la esclavitud en Hairí. Aquél, por su parte, contra todo pronóstico, renunció a asumir un destino de caudillo racista, revanchista e intransigente, en la mejor tradición de los dictadores africanos. Luego de pasar veintisiete años en la cárcel por haberse rebelado con 
tra el sistema de segregación instaurado por los blancos sudafricanos y haber accedido al poder por medio de elecciones libres, incluyentes y transparentes, Mandela simboliza el ejemplo vivo de la dignidad y sentido de la responsabilidad de los sudafricanos.

Para tomar la dimensión exacta de la liberación, sin efusión de sangre y sin revanchismo, de los negros de Sudáfrica, es suficiente recordar que en el mismo momento en que se celebraba la elección de Mandela a la presidencia de su país y que se enterraba el apartheid institucional, en otro país africano muy cercano, Rwanda, estaba realizándose el genocidio étnico entre hutus y tutsis. El saldo fue de varios millones de personas masacradas debido a los odios raciales entre africanos. Por eso, nunca se encontrarán suficientes palabras para calificar lo que pasó en Sudáfrica. Con justa razón que algunos se atreven a hablar de milagro sudafricano.

A diferencia de los demás países africanos, la colonización europea de Sudáfrica tomó desde el principio un cariz distinto y que hubo de marcar el ritmo y la vida en este extenso país de más de un millón de kilómetros cuadrados. Todo empezó el cinco de abril de 1652 , con el desembarco de un centenar de hombres, en la bahía de El Cabo, al mando de Jan van Riebeeck. La misión de esta expedición, que a la postre sería la avanzadilla de la colonización de Sudáfrica, consistía en establecer una escala técnica para los barcos de la Compañía Holandesa de las Indias Orientales. Desde El Cabo, se pretendía producir los víveres, legumbres frescas, carne etc., que necesitaban los que efectuaban, por cuenta de la Compañía, la travesía desde el Océano Índico hasta los Países Bajos.

El primer objetivo de los asentados por la Compañía en esta región africana, no consistía en una colonización propiamente dicha. Aquellos primeros blancos eran empleados de una empresa boyante, cuyo principal objetivo se podía resumir en la idea de cerrar el círculo de sus negocios, en este caso, asegurar la producción a precio bajo de los alimentos que consumían sus tripulantes durante largos viajes en el océano. En esta primera misión encomendada reside, en buena medida, la particularidad de la historia sudafri1 cana, su desarrollo posterior que consolidó, hasta hace diez años, una sociedad jerarquizada, estrictamente organizada según el color de la piel de los individuos, 
en la que los nacionalistas blancos, en buena medida los Afrikaaners, eran la casta privilegiada.

Los Afrikaaners, descendientes de los primeros blancos que llegaron a Sudáfrica, hostiles en su mayoría a la política de aprovisionamiento barato de la compañía, eran, por lo general grandes terratenientes que se dedicaban, gracias a la mano de obra de los nativos reducidos a la esclavitud, a la agricultura y ganadería, entre otras actividades agrícolas. Por lo mismo, se consideraban legitimados debido a la superioridad de su raza, su apego a la tierra, como dignos propietarios que deberían hacer fructificar una tierra legada por Dios, en la auténtica línea de pensamiento de las nuevas sectas protestantes, cuyo apogeo se estaba experimentando en Europa durante esa época.

Los colonos que llegaron en el siglo XVII, pronto se rebelaron en contra del régimen de intercambio instaurado por la companía. No estaban de acuerdo con el hecho de vender barato los productos que tanto les costaban producir. Entonces, desde un principio, la génesis de las relaciones entre los colonos y la compañía, estuvo marcada por el conflicto. La dominación política y comercial exclusiva que reclama- ba para sí la compañía constituía la principal fuente de problemas $y$ de reclamos permanentes. "Por una parte -según René Lefort-, la compañía no quería que mermara el monopolio de producción y de intercambio. Por otra, los empleados-agricultores estaban evidentemente más preocupados en procurar su propio bienestar que en aumentar los beneficios de la compañía".

Finalmente, en contra de los intereses de la compañía, algunos colonos se deshicieron de sus ataduras, penetraron más al interior del territorio, para dedicarse a la agricultura y a la ganadería. Con éstos, se inició la verdadera colonización de Sudáfrica. "En medido de la prolongada tranquilidad del siglo XVIII - nos dice Kiewet- se formó la raza bóer. En este vasto paisaje del interior desprovisto de misterio, abrasador, es donde está el verdadero centro del poblamiento humano sudafricano. Cuando los trekboers llegaron allí con su rebaño y su furgón entoldado, abandonaron el modo de vida europeo y los hábitos económicos de las naciones de donde procedían. (...) Llevaban una vida limitada y sin reposo. Tenían el apetito del nómada por el espacio y poseían la dureza y el valor de los hombres que desde la montura vigilan los rebaños y cazan 
para comer. Su ganado, sus hijos y nietos que nacían y prosperaban de manera asombrosa, constituían toda su riqueza. Esta vida les daba una gran tenacidad, una resistencia silenciosa y un respeto muy vivo de sí mismos".

La penetración exitosa de los colonos holandeses en el territorio africano asentó las bases de una colonización sobre las cuales, algunos siglos más tarde, éstos reivindicarían sus derechos de suelo, su nacionalismo y sus raíces en tierras africanas. Aunque, sin embargo, sus éxitos económicos y su apetito por la tierra se satisfacían expulsando a los pobladores nativos, los negros, eternos víctimas del desarrollo y prosperidad de los blancos. "Esta penetración colonial -observa Lefort- provocó inevitablemente choques con los indígenas: unos y otros practicaban la misma economía y tenían, por lo tanto, las mismas necesidades, de tierras y ganado. Unos años después del desembarco de van Riebeeck, un jefe negro preguntaba ya lo que ocurriría si ellos, los hotentotes, desembarcaran en los Países Bajos y obraran allí como los colonos lo hacían en El Cabo. Muy pronto las relaciones entre indígenas y colonos se dirimieron por la fuerza, y las armas de fuego procuraron a los segundos una ventaja decisiva. Los pueblos indígenas combatidos fueron pura y simplemente objeto de matanzas antes de que huyeran al norte (tal como ocurrió con los bosquimanos), o bien, por un sistema semejante al de las razzias, sojuzgados y progresivamente reducidos a la esclavitud (en el caso de los hotentotes)".

Con estos antecedentes, pronto se establecieron dos ejes paralelos en la política y social de vida en el territorio sudafricano, aunque, al final, profundamente imbricados desde un punto de vista de sus relaciones económicas. Por un lado, los blancos, aquellos que se valieron de sus armas para asentar su autroproclamada superioridad racial e impusieron su ley en la Colonia. Por otro lado, los otros, no blancos, víctimas de la segregación. Los blancos sudafricanos, no obstante sus intereses divergentes - de ello se hablará en los siguientes párrafos-, terminaron entendiéndose para asegurar la perpetuación de su supremacía sobre la mayoría de la población de este país africano.

Desde el principio, existió un malestar perceptible entre los colonos y la Compañía. Ésta, como ya se decía, estaba dispuesta a impedir cualquier tipo de intercambio económico que minara sus ganancias sobre los moradores blan- 
cos de El Cabo. Por eso que la Compañía, en sus momentos gloriosos impulsó la importación de esclavos, procedentes de África Oriental y Madagascar. "Esta decisión, - según Lefort- había de ser el prólogo de una división social con arreglo a un criterio únicamente racial, división que habría de perpetuarse y hacerse cada vez más profunda hasta nuestros días. La raza determina la adscripción, bien sea a un grupo superior, dueño de los medios de producción y de intercambio y que monopoliza todas las funciones de mando, bien, por el contrario a una masa indistinta, intercambiable, forzada a la los trabajos más duros, reducida a la sumisión - y la barrera racial ha[bía] nacido".

En el contexto de las rivalidades entre las potencias europeas por el control de la ruta de las Indias, luego del debilitamiento de lo Países Bajos y del desmoronamiento subsecuente de la Compañía, Inglaterra, en 1795 se instaló en El Cabo. Con ello, llegó una nueva oleada de colonos blancos quienes luego entrarían en competencia con los Afrikaaners y que significarían un yugo mayor para las poblaciones nativas. "En estas condiciones, la coexistencia del imperialismo británico y de todos los segmentos de la sociedad bóer no podría ser ar- moniosa. La burguesía comerciante de El Cabo experimentó un desarrollo considerable gracias a la sustitución de una compañía cada vez más débil por una potencia económica tan vigorosa. (...) Los cultivadores y ganadores bóers limitados a una economía rural atrasada que no se mantenía más que merced a la explotación sin freno y sin medida de una mano de obra negra reducida a la esclavitud y rápidamente renovada, chocaban evidentemente con este sistema librecambista".

$\mathrm{La}$ introducción de la actividad de extracción minera, entre 1867 y 1886 , dominada, al inicio por capital británico, agudizó, por un lado, la tensión entre los blancos $y$, por lado, la miseria y discriminación de las poblaciones no blancas. El elemento central de explotación minera es que hizo del trabajo forzado su principal eje giratorio, para garantizar altas ganancias. Frente a la posibilidad de transferir los altos cosos de producción a los consumidores, la reducción a situaciones de cuasi esclavitud de los negros evitó la crisis y aseguró el enriquecimiento de los blancos. El reclutamiento se llevaba a cabo mediante la economía del trabajo forzado que obligaba a los negros a migrar desde sus comunidades aldeanas al campamento minero. 
Se firmaba un contrato de trabajo obligatorio y una coerción extra-económica, implementada desde el Estado, se puso en marcha la captación de la acumulación capitalista. En 1911, se extendió las sanciones criminales a aquellos que rompían su contrato de trabajo. En 1913 se prohibió a los negros la posibilidad de compra de tierras. Estas decisiones dieron paso a la creación de extensiones territoriales pertenecientes a las comunidades que, luego constituyeron reservas de mano de obra mejor controladas, que migraban directamente a los centros urbanos.

Por otro lado, el hecho de que el estado emprendía acciones directas para favorecer a los empresarios mineros, los conflictos al interior de los blancos, unos agricultores y ganaderos y otros empresarios de la minería e importadores de granos.

Sin embargo, después de varios choques entre la burguesía compradora, promotora del intercambio libre con Inglaterra y los Afrikaaners, nacionalistas, defensores de su autonomía y sus tradiciones de producción agrícola, allanaron sus diferencias en beneficio de sus intereses comunes de marginación de la mayoría, los no blancos. "El pueblo soberano no reconoce igualdad alguna entre los blancos y los individuos de color, lo mismo en la Iglesia que en el Estado. Ningún indígena será autorizado a establecer cerca de los centros de población en detrimento de los habitantes sin un permiso expreso de la totalidad de la Asamblea. Todo indígena debe ser portador de un salvoconducto", decía la constitución del Estado de Transvaal en 1856.

Desde esa fecha, hasta la elección de Mandela a la presidencia de Sudáfrica, este país estaba dividido en dos bloques de ciudadanos, conviviendo en el mismo espacio, bajo el mando de un mismo gobierno, pero con leyes distintas y derechos diferentes según el color de su piel. El icono de la lucha contra el apartbeid, Mandela, a sus 85 años en 2004, es un ejemplo vivo de la crueldad de la segregación racial y de lo que estaban dispuestos a hacer los blancos sudafricanos para reafirmar su ignorante certeza de la inferioridad de los no blancos. Mandela pasó 27 años en una cárcel de máxima seguridad, con muchos períodos largos de confinamiento solitario, con trabajos forzado spor haberse rebelado en contra del sistema. Pero, el padre de la nueva Sudáfrica nunca se dio por vencido, ni mucho menos se dejó doblegar la mano en su pulso en contra de los gobiernos racistas. 
Las leyes de segregación racial en Sudáfrica contaron siempre con el beneplácito del gobierno británico. Pese a las reticencias de inicio - los ingleses habían declarado que "fuera del territorio muy limitado que es necesario para la seguridad de El Cabo, como base naval, los únicos motivos que nos hacen actuar en Sudáfrica son la protección de nuestros fieles súbditos y el deseo filantrópico de promover el cristianismo y la civilización"-, las autoridades británicas se acomodaron con la esclavitud y la segregación de los no blancos, para evitar cualquier diferendo que pusiera en peligro sus buenas relaciones con sus pares sudafricanos.

Cuando en 1910 se estableció la unión entre las Repúblicas Bóers del Estado Libre de Orange y de Transvaal; y las regiones del Cabo y Natal dominadas por ingleses, uno de los puntos fundamentales del acuerdo establecía el sufragio sólo para blancos en las primeras, mientras que en las segundas se mantuvo el sufragio sin discriminación racial. En opinión de los historiadores de la cuestión sudafricana, esta última decisión se debía al objetivo de los afrikaaners de conservar su identidad nacional que descansa, en últimas instancias en la creencia racista según la cual Dios mismo estableció la diferencia entre blancos y negros y dictaminó la supremacía de los primeros.

El Partido Nacionalista (o partido Afrikaaner), creado en 1914, no sólo se adhirió a la idea de defender de manera militante la creencia de la superioridad de los blancos, sino que se proclamó abiertamente esta política interna del dominio de la población blanca. En este contexto, su puso en marcha el apartbeid, en su versión más actual, hacia los años cincuenta. Dicho de otra manera, la ideología de la segregación de las razas fue la continuación y el perfeccionamiento del viejo sistema de segregación, heredado desde los primeros días de la colonia.

En fin, se puede decir que la intervención del Estado sudafricano en su versión blanca, tenía como objetivo el mantenimiento a grupos raciales en categorías sociales diferentes. De esta manera, no sólo se daba fiel cumplimiento al precepto racista de la supremacía blanca, sino que también se perpetuaba para las generaciones venideras las desigualdades, políticas, económicas y sociales. Algunas de las leyes que se adoptaron y que perseguían el segregacionismo esta intención son las siguientes: La ley de reforma electoral de 1948 que fijó los requisitos para la inscripción de los vo- 
tantes no blancos en los lugares donde se les permitía sufragar. Así, se les negaba toda posibilidad de participación política. De esta manera, se aseguraba que la minoría blanca pudiera ejercer el domino político del Estado.

También, en 1950, se prohibieron los matrimonios mixtos y se fomentó el control de las migraciones de la mano de obra negra hacia las ciudades para asegurar al sistema un ejército de reserva de trabajadores. "Los trabajadores africanos no podían permanecer por más de 72 horas en las áreas blancas y además se prohibió todo derecho a huelga, dejando indefensos a los trabajadores no blancos frente a los patrones, con salarios sumamente bajos. Otra de las estrategias para sujetar firmemente a la población africana nativa fue la de controlar el sistema educacional orientándolo hacia los fines del apartheid. La política educativa se orientó a que los nativos acepten su inferioridad. En 1954 se dio un paso más en esta política al transferir el costo de la financiación escolar a los propios africanos. Esta misma legislación sobre educación bantú fue completada en 1959 con la Ley de Extensión de la Educación que prohibió la matrícula de estudiantes no blancos en las universidades".
En febrero de 1990, luego de las revueltas internas, combinadas con una presión mayor de la comunidad internacional, el gobierno blanco levantó las sanciones contra las organizaciones políticas opuestas al apartheid y legalizó al Congreso Nacional Africano, dirigido por Nelson Mandela. Estos pasos fueron los primeros resultados de un largo proceso de lucha para desmantelar el régimen segregacionista.

La supresión del apartbeid, si bien significó el ascenso de la población negra al poder político, gracias a las elecciones multirraciales celebradas en 1994, los problemas sociales continúan porque no es posible cambiar bruscamente una ideología racista fuertemente arraigada en la población. Las resistencias y los resentimientos son demasiado fuertes para plantear una salida que tienda a dar respuestas viables a las condiciones de vida de la población nativa.

En este sentido, cabe preguntarse por las condiciones del desarrollo capitalista en este período que se ha despojado, al menos en el plano institucional, de sus fundamentos ideológicos. Tal vez, una posible explicación puede buscarse en el hecho de que si bien ha cedido terreno en el pla- 
no político, en el económico sigue teniendo la hegemonía. Mientras no se den conquistas en el ámbito económico, las transformaciones políticas no podrán por sí mismas generar cambios profundos.

Ahora bien, la conmemoración del aniversario de los diez años del fin del apartheid, no se puede afirmar que todo se ha vuelto a la normalidad en Sudáfrica. Como es evidente, difícilmente se podrá arreglar en diez años, cinco siglos de segregación y de exclusión planificada desde las más altas esferas de las instituciones políticas. En este sentido, en opinión de muchos estudiosos de la situación sudafricana, el país sigue viviendo una segregación de hecho, entre una gran mayoría de negros pobres y una minoría de blancos. En este sentido, el ascenso al poder estatal de los negros, la derogación de las leyes de segregación y el aire fresco que sopla sobre este país africano no han sido suficientes para erradicar las consecuencias del apartheid. Se estima que veinte millones de negros, sobre una población treinta seis millones sobreviven con 334 rands (alrededor de 50 dólares) por mes. Además, se ha disparado la inseguridad ciudadana, la delincuencia organizada y crímenes crapu- losos de toda clase campean en las ciudades sudafricanas.

Decía Thabo Mbecki, en 1999, luego de su primera elección a la presidencia sudafricana, que para erradicar el racismo es necesario crear y asentar una clase de capitalistas negros. Desde entonces, ocho millones de negros son considerados como pertenecientes a la clase media y alta. Se han promovido acciones de discriminación positiva que obligan y premian a las empresas que incorporen a los negros a las más altas esferas de decisiones ejecutivas.

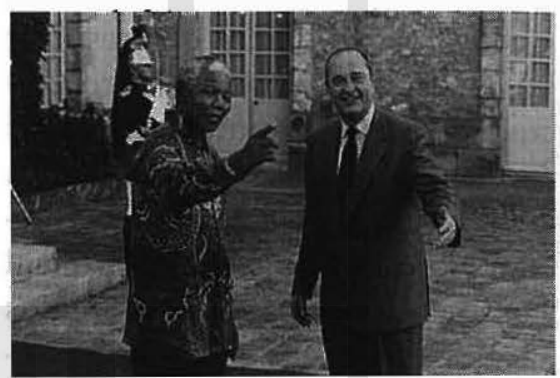

nuevo camino. Lo más probable, no obstante las desigualdades chocantes entre los pobres (ahora muchos de ellos también son blancos) y los ricos (incluidos algunos de los negros que han aprovechado los nuevos cambios políticos para subir peldaños importantes en la sociedad) que este país podrá superar la apuesta por una integración y co- 
existencia pacífica entre ciudadanos de distinta raza, luego de los siglos de segregación. A este respecto, quizás pueda ser de mucha utilidad repetir las palabras de Olive Schreiner, en Ciudad del Cabo en 1966:

"Los problemas del siglo XX (se diría ahora el siglo XXI) no serán una repetición de los del siglo XIX o de cualquier siglo anterior. Las murallas que dividen los continentes se están derrumbando; europeos, asiáticos y africanos se mezclarán en todas partes. El mundo de principios del siglo XXI será muy diferente del de comienzos del siglo XX. Y el problema que este siglo tendrá que resolver es el de realizar este entrelazamiento de las distintas variedades humanas en la forma más amplia y beneficiosa posible, para contribuir al desarrollo de la humanidad como un todo, en armonía con los ideales modernos y las necesidades sociales modernas".

"[Los sudafricanos son] uno de los primeros pueblos del mundo moderno que deben enfrentar este problema en su forma más aguda y en las nuevas condiciones morales y materiales de la civilización. [Su] grandeza dependerá de [su] poder para resolverlo con altura y heroísmo. Si a partir de [su] gran complejo humano (cuyas partes quizá permanezcan diferenciadas racial- mente durante siglos) se logra edificar una nación libre, inteligente y armoniosa, cada una de cuyas partes opere en beneficio de las restantes, entonces se habrá desempeñado un papel tan grande como el de cualquier otra nación de la historia del mundo. Así como actualmente volvemos nuestros ojos a Grecia, o a Roma, o a Inglaterra en busca de modelos para todas aquellas cosas en las que se han destacado, las naciones futuras, sea cual fuere su clase dominante, están obligadas a volver sus ojos a Sudáfrica y seguir su guía, diciendo: La de ellos fue la primera y la verdadera solución del problema".

\section{BIBLIOGRAFÍA}

De Beer, Z. J., Sudáfrica y el problema de las razas, Editorial Universitaria de Buenos Aires, Buenos Aires, 1963.

Claude Patrice, "Les nouveaux élus", Le monde, 27 de abril de 2004

Lefort, René, Sudáfrica: bistoria de una crisis, Siglo Veintiuno Editores, Madrid, 1978.

Pompey, F. y Smich, S. "L'Afrique du sud celebre la fin de l'apartheid", Le Monde, 27 de abril de 2004.

Servicios de Información Pública, Apartheid el trato dado a los presos en Sudáfrica, Naciones Unidas, Nueva York, 1968

"Dans la nation Arc-en-ciel les difficultés d'un couple multicolore"; Le monde, 27 de abril de 2004. 